\title{
"The effect of Dow Jones Sustainability Index on Consumer Sentiment Index"
}

\begin{tabular}{ll} 
AUTHORS & $\begin{array}{l}\text { Nikolaos Sariannidis } \\
\text { Grigoris Giannarakis } \\
\text { Xanthi Partalidou } \\
\text { Bakas Evangelos }\end{array}$ \\
& $\begin{array}{l}\text { Nikolaos Sariannidis, Grigoris Giannarakis, Xanthi Partalidou and Bakas } \\
\text { Evangelos (2017). The effect of Dow Jones Sustainability Index on Consumer } \\
\text { Sentiment Index. Investment Management and Financial Innovations, 14(1), 89- } \\
\text { 95. doi:10.21511/imfi.14(1).2017.09 }\end{array}$ \\
\hline ARTICLE INFO & http://dx.doi.org/10.21511/imfi.14(1).2017.09 \\
\hline DOI & Friday, 31 March 2017 \\
\hline RELEASED ON & $\begin{array}{l}(c c) \text { EY-No } \\
\text { This work is licensed under a Creative Commons Attribution-NonCommercial } 4.0 \\
\text { International License }\end{array}$ \\
\hline JOURNAL & "Investment Management and Financial Innovations" \\
\hline ISSN PRINT & $1810-4967$ \\
\hline ISSN ONLINE & $1812-9358$ \\
\hline PUBLISHER & LLC “Consulting Publishing Company “Business Perspectives" \\
\hline FOUNDER & LLC “Consulting Publishing Company “Business Perspectives"
\end{tabular}

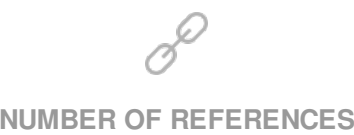

20

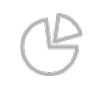

NUMBER OF FIGURES

1

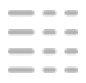

NUMBER OF TABLES

5

(C) The author(s) 2022. This publication is an open access article. 


\title{
Nikolaos Sariannidis (Greece), Grigoris Giannarakis (Greece), Xanthi Partalidou (Greece), Bakas Evangelos (Greece) \\ The effect of Dow Jones Sustainability Index on Consumer Sentiment Index
}

\begin{abstract}
This study intends to investigate whether stock returns affect the consumer sentiment. In particular, socially responsible companies are incorporated in the sample in order to capture the specification of socially responsible investors. For this reason, the University of Michigan Consumer Confidence Index is used as a proxy for consumer confidence, while data from Dow Jones Sustainability Index US is employed as a proxy for socially responsible companies for the period 1999-2016. The generalized autoregressive conditional heteroskedasticity model applied and illustrated that stock returns affect positively the consumer confidence. The result has important implications for investors and policy makers.
\end{abstract}

Keywords: Consumer Confidence, Dow Jones Sustainability Index, GARCH Model, US.

JEL Classification: C58, Q40, Q50, M21.

\section{Introduction}

Several studies have investigated the relationship between stock returns and consumer confidence. In particular, a number of studies investigated the role of consumer sentiment on stock returns (e.g. Chen, 2011; Chen, 2015). However, less interest has been focused on whether stock returns affect consumer confidence. To our knowledge, no study incorporates the effect of socially responsible stock return on consumer confidence.

Consumer confidence is an important variable for investors, firms, governments and other bodies since a shift of consumer confidence can be a signal for the state of the economy and their own financial situation (Chen, 2015). Further studies suggested that consumer confidence is highly related with the real consumption, forecasting future changes in household spending (Carroll et al., 1994). Similarly, Ludvigson (2004) showed that consumer confidence is correlated with the level of economic activity, while Chen (2011) stated that it can be a significant factor in business cycle fluctuation. Blanchard (1993) suggested that the loss of consumer confidence can lead consumers to decrease the consumption, which is possible to trigger a recession. Finally, Howrey (2001) illustrated that consumer senti-

\footnotetext{
(C) Nikolaos Sariannidis, Grigoris Giannarakis, Xanthi Partalidou, Bakas Evangelos, 2017.

Nikolaos Sariannidis, Professor, Department of Accounting and Finance, Western Macedonia University of Applied Sciences, Greece.

Grigoris Giannarakis, Adjunct Professor, Department of Business Administration (Grevena), Western Macedonia University of Applied Sciences, Greece. Xanthi Partalidou, Ph.D. Candidate, Department of Agricultural Development Pantazidou, Democritus University of Thrace, Greece. Bakas Evangelos, Postgraduate student, Department of Accounting and Finance, Western Macedonia University of Applied Sciences, Greece.

This is an Open Access article, distributed under the terms of the Creative Commons Attribution-NonCommercial 4.0 International license, which permits re-use, distribution, and reproduction, provided the materials aren't used for commercial purposes and the original work is properly cited.
}

ment is a predictor of the future real GDP and statistically significant of the probability of recession.

For all the above reasons, it is vital to ascertain, what factors determine the level of consumer confidence. Undoubtedly, Michigan Consumer Confidence Index is the most well-known and cited confidence index incorporating "news" on future productivity that has long lasting effects on economy like aggregate consumption (Ahmed and Cassou, 2016).

Otoo (1999) revealed that changes in equity values and changes in consumer sentiment are contemporaneously correlated. In addition, increase of equity prices can boost future consumer confidence by employing data from the Wilshire 5000 stock price. According to Otoo (1999), there are two main channels that higher stock returns may lead to increase consumer confidence. The first one is the wealth channel, in which consumers have greater levels of sentiment, because they are wealthier as a result of higher levels of stock returns. The second channel is the leading indicator effect because the consumer considers higher levels of stock prices as a sign of favorable economic conditions and potential labor income growth in the future.

Additionally, Hsu et al. (2011) used a panel Granger-causality framework in order to investigate the casual relationship between consumer confidence and stock markets, applied in 21 country for the period 1999-2007. The results supported that stock returns Granger-cause changes in consumer confidence and vice versa. The effect of wealth on consumption is considered a factor for the one-way causality from stock returns to the change in consumer confidence. A second reason is that stock market is a leading indicator for the future income and economic growth, consumers will maintain a positive attitude toward future economic conditions.

Furthermore, Jansen and Nahuis (2003) incorporated 11 European countries in order to examine the relationship between stock market developments 
and consumer confidence for the period 1986-2001. The results illustrated that, except for Germany, there is a positive correlation between two variables. In general, stock returns generally Granger-cause consumer confidence at very short horizons, but not vice versa. The expectations for the economy is the main factor that determines the relationship between stock market and consumer confidence.

Finally, Chen (2012) used data from Standard and Poor (S\&P) 500 in order to ascertain if stock returns have asymmetric effects on Conference Board Consumer Confidence Index as a proxy of consumer confidence for the period 1969-2007. The results suggested that there is an asymmetric linkage between stock returns and consumer confidence. In particular, the impacts of stock returns on consumer confidence are larger in bear markets. However, when Michigan Consumer Sentiment Index (CSI) was used as a proxy of consumer confidence, it was found to have a weak effect of returns on consumer confidence.

This study was triggered to employ stock returns of socially responsible companies, as prior empirical studies focused on conventional group of companies. Socially responsible firms intend to maximize shareholders' values along with stakeholders' needs. During the last two decades, socially responsible investors tend to invest in companies that incorporate in their business operations social and environmental initiatives towards the concept of sustainable development (Popa, 2014; Bendell and Kearins, 2005). In most of the cases, Socially Responsible Investments (SRI) have attracted the interest as commentary or rival investment to conventional ones (Sirbu et al., 2014).

Global Sustainable Investment Alliance in 2004 presents that socially responsible investments have been increased dramatically. For the period 2012 to 2014, the fastest growing region for SRI is the US followed by Canada, Europe, Australia/New Zealand and Asia with two years growth $76 \%, 60 \%$, $55 \%, 34 \%$ and $32 \%$, respectively. The total value of SRI globally increased from $\$ 13.261$ to $\$ 21.358$ billion, while the total proportion of SRI relative to total managed assets was increased from $21.5 \%$ to $30.2 \%^{1}$. In the US, both Dow Jones and S\&P stock markets provide stock market indexes incorporating companies that integrate in their operations both environmental and social criteria.

This study intends to investigate, whether stock returns of socially responsible companies affect the

\footnotetext{
${ }^{1}$ Global Sustainable Investment Alliance, (2014). 2014 Global Sustainable Investment Review. Available at: http://www.gsi-alliance.org/wp content/uploads/2015/02/GSIA_Review_download.pdf (Accessed on 25 November, 2016).
}

consumer confidence level in the US. For this reason, the Michigan Consumer Sentiment Index as a proxy of willingness of consumer to spend money. In addition, Dow Jones Sustainability Index (DJSI) the US data are employed for the first time in order to incorporate in the proposed model companies that integrate socially and environmental companies.

Additionally, to account for other determinants that could affect consumer confidence, it considers two control variables, namely, crude oil and international trade balance, taking into account the period from September, 1999 to May, 2016.

The structure of the paper is as follows: The following section presents information for the data and the methodology employed. The second section presents the results of the analysis, while the final section incorporates the conclusions of the study.

\section{Methodological approach and data}

As far as the methodological approach is concerned, the autoregressive conditional heteroskedasticity (ARCH) model developed by Engle (1982), and extended by Bollerslev (1986) and Nelson (1991), allows the fat tails and imposes an autoregressive structure on the conditional variance, thus it is capable of capturing not only the volatility persistence of return series over time, but also the volatility clustering as well. The estimation of GARCH model involves the joint estimation of a mean and a conditional variance equation. The GARCH $(1,1)$ model is stated as follows:

The mean equation

$Y_{t}=X_{t}^{\prime} b+u_{t}$,

where $X_{t}$ is a vector of exogenous variables.

The conditional variance equation

$\sigma_{t}^{2}=c_{0}+c_{1} u_{t-1}^{2}+c_{2} \sigma_{t-1}^{2}$.

The conditional variance equation is a function of three terms:

$c_{0}$ : A constant term.

$c_{1} u_{t-1}^{2}$ (the ARCH term): News about volatility from the previous period, measured as the lag of the squared residual $u_{t-1}^{2}$ from the mean equation.

$c_{2} \sigma_{t-1}^{2}$ (the GARCH term): Last period's forecast variance as a function of the past residuals $u_{t-2}, u_{t-3}, \ldots$.

$c_{1}+c_{2}<1$ : It should be noted that this constrain allows the process to remain stationary, with the upper limit $c_{1}+c_{2}=1$, which represents an integrated process. 
Regarding the variables employed in the proposed model, the University of Michigan CSI is used in this study as a proxy for consumer confidence published monthly by the Survey Research Center at the University of Michigan. Personal and telephone interviews are employed from a wide national sample under multistage area probability sampling. Each respondent should answer five questions under different types of answers, such as (1) up, better, or good; (2) same, no change, or uncertain; and, (3) down, worse, or bad' (Huth et al., 1994). Two out of five questions concern the current business conditions, while the rest of the questions regard the future business conditions (Singal, 2016). The use and the value of University of Michigan CSI have been used intertemporally by prior empirical studies such as Curtin (1982), Huth et al. (1994), Singal (2016) and Ahmed and Cassou (2016). In particular, CSI contains measures of attitudes toward personal finances, general business conditions, and market conditions or prices, so as to determine the changes in consumers' willingness to buy and to predict their subsequent discretionary expenditures. Data for CSI variable was retrieved by Bloomberg online platform.

As far as DJIS is concerned, it provides the opportunity to investors to create portfolios of companies assessed under sustainable criteria. To satisfy the specific needs of the investor, DJSI incorporates a number of sub-indexes excluding specific industries that operate, such as tobacco, gambling, armaments, cluster bombs and firearms ${ }^{3}$. As far as DJSI US is concerned, it comprises US sustainability leaders, as according to RobecoSAM approach representing the top $20 \%$ of the largest 600 U.S. companies in the Dow Jones Sustainability ${ }^{\mathrm{TM}}$ North America ${ }^{4}$. Under the prism of transparency, RobecoSAM publishes the criteria weight for all industries on the Corporate Sustainability Assessment. The most important advantage of the methodology is the recommendation of both general and industry-specific criteria in order to capture the specific specifications of each industry ${ }^{5}$, while the weight of each criterion depends

\footnotetext{
${ }^{2}$ Full length of questionnaire is available from University of Michigan: https://data.sca.isr.umich.edu/fetchdoc.php?docid=24776 (Accessed on 25 November, 2016).

${ }^{3}$ S\&P Dow Jones Indices: Dow Jones Sustainability Indices Methodology and RobecoSAM (2016), Dow Jones Sustainability Indices Methodology: https://www.djindexes.com/mdsidx/downloads/meth_info/metho dology-dj-sustainability-indices.pdf.

${ }^{4}$ Dow Jones Sustainability United States Index - Factsheet (2016) http://djindexes.com/mdsidx/downloads/fact_info/Dow_Jones_Sustaina bility_United_States_Index_Fact_Sheet.pdf (Accessed on 20 November, 2016).

5 RobercoSAM (2016), 2016 RobecoSAM Corporate Sustainability Assessment - Annual Scoring and Methodology Review. Available at: http://www.robecosam.com/images/CSA_2016_Annual_Scoring_Meth odology_Review.pdf (Accessed on 20 November, 2016).
}

on the industry that the company operates ${ }^{6}$. Data for DJSI US were obtained by the official site of $\mathrm{DJSI}^{7}$.

As far as control variables are concerned, this study selects crude oil prices and international trade balance. Regarding crude oil prices, it is available by the U.S. Energy Information Administration. Chen (2012) supported a negative effect of oil prices on consumer confidence. Data for crude oil were retrieved by the US Energy Information Administration $^{8}$. Furthermore, the international trade balances are expected to affect the consumer confidence. The international trade measures the difference between the movement of merchandise trade leaving a country (exports) and entering a country (imports) tracking the value of the merchandise trade. Data for retrieved by Bloomberg on-line platform.

Monthly continuously compounded returns for the selected data are calculated as, $R_{t}=100 * \log \left(p_{t} / p_{t-1}\right)$, where $R_{t}$ and $p_{t}$ are the daily returns and prices respectively.

\section{Empirical findings}

Table 1 presents the summary statistics for CSI, DJSI, CRUDE, and EXPORT series. Specifically, no conclusion about the overall sign of the skewness can be reached as some series show positive skewness and some negative one. The first three series, CSI, DJSI and CRUDE, present some characteristics that are known as stylized fact (Cont, 2001). In particular their returns distribution is leptokurtic with fat tails (Kurtosis > 3), which means that in the context of a model the normal distribution will underestimate the number and magnitude of crashes and booms. Also, the distribution of their returns is negatively skewed, indicating that extreme negative returns are more frequent than extreme positive returns. The non-normality of their distribution is confirmed by the statistic test of Jarque Bera. On the contrary, the return series of export exhibit mesokurtosis (Kurtosis $=2.9 \approx 3$ ), and the skewness value of 0.29 indicate a slightly positive skewed distribution suggesting proximity to normal distribution, a fact that is confirmed by the significance of Jarque Bera statistic. Finally, the augmented Dickey Fuller (ADF) test, allowing for both an intercept and a time trend, showed that the sample series had been produced by stationary series.

\footnotetext{
${ }^{6}$ RobercoSAM (2016), RobecoSAM Corporate Sustainability Assessment 2016. Available at: http://www.robecosam.com/images/Robeco SAM_Sustainability_Assessment_Weightings_2016.pdf (Accessed on 20 November, 2016).

7 Data for DJSI US available at: Data for DJSIW available at: http://www.sustainability-indices.com/index-values/ (accessed on 1 November, 2016).

${ }^{8}$ Data for crude oil available at: https://www.eia.gov/dnav/pet/pet _pri_spt_s1_d.htm (accessed on 1 November, 2016).
} 
Table 1. Sample statistics

\begin{tabular}{|l|c|c|c|c|}
\hline & CSI & DJSI & CRUDE & EXPORT \\
\hline Mean & -0.00049 & 0.0031 & 0.0039 & 0.0038 \\
\hline Median & -0.00327 & 0.00896 & 0.0153 & 0.0031 \\
\hline Maximum & 0.12762 & 0.0991 & 0.2139 & 0.1798 \\
\hline Minimum & -0.19925 & -0.18769 & -0.332 & -0.1529 \\
\hline Std. dev. & 0.05375 & 0.04516 & 0.0898 & 0.0671 \\
\hline Skewness & -0.36374 & -0.64785 & -0.8416 & 0.2915 \\
\hline Kurtosis & 3.76580 & 4.23517 & 4.416 & 2.9006 \\
\hline Jarque-Bera & 9.34 & 26.8378 & 40.50 & 2.92 \\
\hline Observations & 201 & 201 & 201 & 201 \\
\hline Augmented Dickey-Fuller (ADF) & -11.93 & -13.34 & -10.40 & -4.68 \\
\hline
\end{tabular}

Table 2 shows the sample autocorrelation function (ACF) and partial autocorrelation function (PACF) for monthly returns and squared monthly returns of the CSI series. It can be observed that the Ljung - Box statistics provide evidence of autocorrelation on monthly returns and present strong evidence of autocorrelations in the squared monthly returns, indicating conditional heteroskedasticity (Bollerslev, 1987).

Table 2. Test for serial dependence in the first and second moments of CSI series

\begin{tabular}{|c|c|c|c|c|c|c|c|}
\hline \multicolumn{4}{|c|}{ Returns } & \multicolumn{4}{c|}{ Squared returns } \\
\hline Lags & Autocorrelation & Partial Correlation & $\mathrm{LB}(\mathrm{n})$ & Lags & Autocorrelation & Partial correlation & $\mathrm{LB}(\mathrm{n})$ \\
\hline 1 & -0.011 & -0.011 & 0.0253 & 1 & 0.075 & 0.075 & 1.138 \\
\hline 2 & -0.177 & -0.177 & 6.4668 & 2 & 0.032 & 0.026 & 1.3443 \\
\hline 3 & -0.134 & -0.143 & 10.173 & 3 & 0.088 & 0.084 & 2.9361 \\
\hline 4 & 0.008 & -0.032 & 10.187 & 4 & 0.056 & 0.043 & 3.5798 \\
\hline 5 & -0.015 & -0.069 & 10.235 & 5 & 0.15 & 0.141 & 8.2876 \\
\hline 6 & 0.053 & 0.028 & 10.826 & 6 & 0.138 & 0.114 & 12.286 \\
\hline 12 & 0.075 & 0.06 & 17.557 & 12 & 0.011 & 0.008 & 14.091 \\
\hline 24 & 0.04 & -0.031 & 29.194 & 24 & -0.052 & -0.055 & 19.21 \\
\hline 36 & 0.018 & 0.071 & 54.97 & 36 & -0.033 & -0.001 & 62.279 \\
\hline
\end{tabular}

Notes: LB(n) are the n-lag Ljung-Box statistics for $\operatorname{CSI}_{t}$ and $\operatorname{CSI}_{t-1}^{2}$ respectively. LB(n) follows chi-square distribution with $\mathrm{n}$ degree of freedom; the sample period contains 201 monthly returns.

In summary, it seems that the CSI return series is best described by an unconditional leptokurtic distribution and possesses significant conditional heteroskedasticity. This renders the ARCH models a very good choice for modelling the CSI return series.

The preliminary statistical results and the application of the LR test on the GARCH(p,q) model demonstrated the final specification for the estimation of the mean and volatility for the CSI series. The specification is:

Mean equation:

$C S I_{t}=b_{1}+b_{2} C S I_{t-1}+b_{3} D J S I_{t-1}+b_{4} C R U D E_{t-1}+$

$+b_{5} E X P O R T_{t-2}+u_{t}$.

Variance equation:

$\sigma_{t}^{2}=c_{0}+c_{1} u_{t-1}^{2}+c_{2} \sigma_{t-1}^{2}$,

$u_{t} \sim \operatorname{GED}\left(0, \sigma_{t}^{2}\right)$.
Some diagnostic tests were performed to establish goodness of fit and appropriateness of the model. First, it was examined whether the standardized residuals and squared standardized residuals of the estimated model were free from serial correlation. As we can see at Table 3, the LB(n) statistics for standardized residuals are not statistically significant and the $\mathrm{LB}(\mathrm{n})$ statistics for standardized squared residuals show no $\mathrm{ARCH}$ remaining structure. Furthermore, the coefficient estimation $\mathrm{v}=1.567$ for tail thickness regulator with 0.28 standard error, confirms the adoption of the GED assumption. Specifically, the assumption of normal distribution is rejected, a fact that verifies the theory for thick tails in the stock returns. An LR test of the restriction $\mathrm{v}=2$ (for $\mathrm{v}=2$ the GED distribution is essentially the normal distribution) against the unrestricted models clearly supports this conclusion.

Table 3. Diagnostics on standardized and squared standardized residuals

\begin{tabular}{|c|c|c|c|c|c|c|c|}
\hline \multicolumn{4}{|c|}{ Residuals } & \multicolumn{5}{c|}{ Squared residuals } \\
\hline Lags & Autocorrelation & Partial correlation & $\mathrm{LB}(\mathrm{n})$ & Lags & Autocorrelation & Partial correlation & LB(n) \\
\hline 1 & -0.059 & -0.059 & 0.6992 & 1 & 0.046 & 0.046 & 0.4216 \\
\hline 2 & -0.112 & -0.116 & 3.2247 & 2 & -0.021 & -0.023 & 0.5077 \\
\hline 3 & -0.136 & -0.153 & 6.954 & 3 & 0.037 & 0.039 & 0.7886 \\
\hline
\end{tabular}


Table 3 (cont.). Diagnostics on standardized and squared standardized residuals

\begin{tabular}{|c|c|c|c|c|c|c|c|}
\hline \multicolumn{4}{|c|}{ Residuals } & \multicolumn{4}{c|}{ Squared residuals } \\
\hline Lags & Autocorrelation & Partial correlation & LB(n) & Lags & Autocorrelation & Partial correlation & LB(n) \\
\hline 4 & -0.066 & -0.105 & 7.8517 & 4 & -0.005 & -0.009 & 0.7935 \\
\hline 5 & 0.01 & -0.042 & 7.8715 & 5 & 0.117 & 0.12 & 3.591 \\
\hline 6 & 0.029 & -0.018 & 8.0413 & 6 & -0.02 & -0.034 & 3.6732 \\
\hline 12 & 0.021 & 0.05 & 12.219 & 12 & -0.006 & 0.035 & 14.455 \\
\hline 24 & -0.002 & -0.031 & 18.2 & 24 & -0.046 & -0.047 & 19.348 \\
\hline 36 & -0.019 & 0.008 & 44.067 & 36 & -0.029 & 0.105 & 47.444 \\
\hline
\end{tabular}

Notes: LB(n) are the n-lag Ljung-Box statistics for the residual series. LB(n) follows chi-square variable with $\mathrm{n}$ degree of freedom; the series of residual contains 200 elements.

Results presented in Table 4 show that the mean return of the CSI series had statistically significant higher return at the $1 \%$ level, when the returns of DJSI have increased, a fact that can be attributed to the wealth effect and the general optimism for the future of economy, as the rising stock markets may make consumers feel better about the future, and so induce them to spend more.

Also, the sign and the statistically significance of the crude oil coefficient imply the vital gravity of energy prices on the economy, and thus on the consumer confidence. Finally, coefficient of US exports suggests the important role in the US economy, reflecting the competitiveness, the exchange rates, the long run productivity and the economic growth of other countries.

In Table 5 the results of the variance equation are presented. The GARCH persistent parameter $\left(c_{2}\right.$ coefficient) is high (0.859), which indicates that old news has a substantial persistent effect on price change. On the contrary, the ARCH coefficient $\left(c_{1}\right)$ parameter is low (0.096), suggesting also that current news has small reaction in prices changes (Figure 1). The sum of the $c_{1}+c_{2}=0.097$ $+0.859=0.956$ is lower than unity, but approaches unity, a fact that indicates the returns volatility of the consumer confidence returns exhibit long memory. The volatility persistence can also be confirmed by the formula of half-life of a volatility shock $\frac{\log (0,5)}{\log \left(c_{1}\right)+\log \left(c_{2}\right)}$, which gives the average number of time periods for the volatility to revert to its long run level. The men reverting rate of $c_{1}+c_{2}=0.956$ is $\ln (0.5) / \ln (0.956)=76.5$ months implying that the conditional volatility of the consumer confidence is quite persistent.

Table 4. Mean equations

$$
\begin{aligned}
& C_{C S I_{t}}=b_{1}+b_{2} \text { CSI }_{t-1}+b_{3} \text { DJSI }_{t-1}+b_{4} \text { CRUDE }_{t-1}+ \\
& +b_{5} \text { EXPORT }_{t-2}+u_{t} .
\end{aligned}
$$

\begin{tabular}{|c|c|c|c|c|}
\hline$b_{1}$ & $b_{2}$ & $b_{3}$ & $b_{4}$ & $b_{5}$ \\
\hline-0.00168 & -0.100292 & $0.381023^{*}$ & $-0.11587^{\star}$ & $0.107533^{\star}$ \\
\hline$(0.003209)$ & $(0.06874)$ & $(0.073471)$ & $(0.0382)$ & $(0.046221)$ \\
\hline
\end{tabular}

Notes: Standards errors are shown in parentheses. *indicates statistical significance at the $1 \%$ level.

Table 5. Variance equations

$$
\sigma_{t}^{2}=c_{0}+c_{1} u_{t-1}^{2}+c_{2} \sigma_{t-1}^{2}
$$

\begin{tabular}{|c|c|c|}
\hline$c_{0}$ & $c_{1}$ & $c_{2}$ \\
\hline 0.00012 & $0.096559^{\star \star *}$ & $0.859513^{\star}$ \\
\hline$(0.000114)$ & $(0.05655)$ & $(0.081969)$ \\
\hline
\end{tabular}

Notes: Standards errors are shown in parentheses. $*$ indicates statistical significance at the $1 \%$ level. $* *$ indicates statistical significance at the $5 \%$ level.

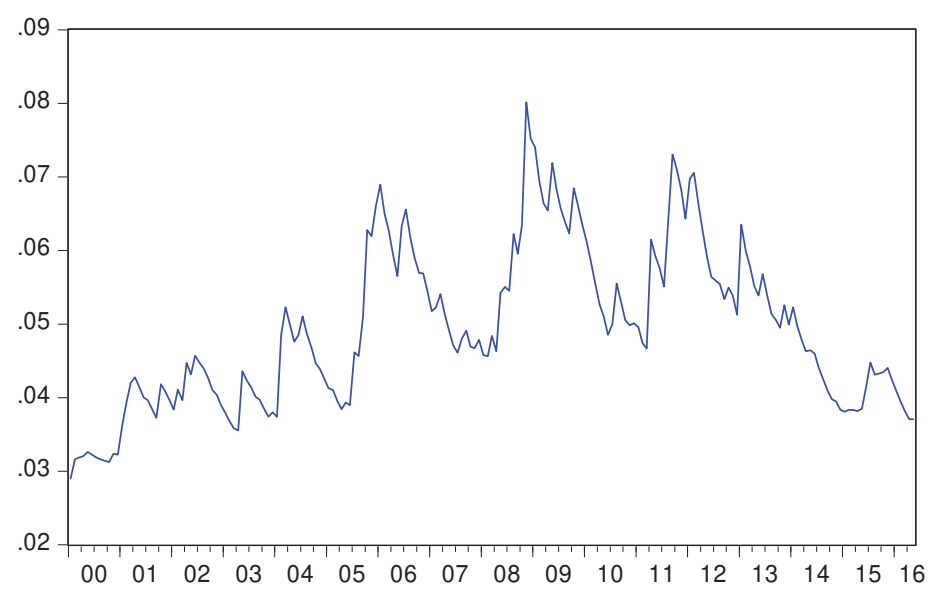

- Conditional standard deviation

Fig. 1. Conditional volatility estimated from modeling $\operatorname{GARCH}(1,1)$ 


\section{Conclusions}

This study intends to investigate the impact of stock returns on consumer confidence. As far as consumer confidence is concerned, the University of Michigan CSI is employed in this study, as it is considered among the most used and reliable proxies for consumer confidence. The novelty of the study stands on the fact that it incorporates the companies that integrate economic, environmental and social factors that are relevant to the companies' success contributing thus on sustainable development. For this reason, data from DJSI US are used as a proxy for socially responsible companies' operation. The US is selected because it is considered among the most pioneer countries for the contribution of sustainable development. A GARCH model is developed in order to ascertain, if DJSI US stock returns affect the CSI composed by the University of Michigan.

As it is found all variables are statistical with a lag reaction, because the results of the University of Michigan CSI are published with a month delay.

The results revealed that stock returns have a positive effect on consumer confidence consistent with Otoo (1999) and Jansen and Nahuis (2003). In general, it seems that the movements of socially responsible stock returns may influence the consumer confidence of US consumers. Thus, wealth effect channel and leading indicator effect can be used in order to explain the above relationship of the two variables. Consequently, the results suggest that both conventional and socially responsible stock indexes returns affect the consumer confidence level. It is very useful for investors and policy makers to understand the factors of consumer sentiment level because of the possible implications for consumption.

As it was expected, all control variables determine the consumer confidence level. In particular, increase of oil prices is interpreted as a negative concern for the current and future economy expecting increased price levels leading to decrease of consumer confidence.

Another evidence of this study indicates that the international trade balance has a positive effect on consumer confidence. A positive balance of international trade in US creates an optimistic mood to consumers for the prosperity of economy such as growth of employment inducing an increase of their confidence level.

Future studies should incorporate different indexes socially responsible indexes such as S\&P 500 Environmental \& Socially Responsible Index and consumer confidence. In addition, studies should be elaborated both in developed and developing economies in order to record differences and similarities for the relationship between the stock price of socially responsible companies and consumer confidence.

\section{References}

1. Ahmed, M. I., and Cassou, S. P. (2016). Does consumer confidence affect durable goods spending during bad and good economic times equally? Journal of Macroeconomics, 50, 86-97.

2. Aloui, R., and Ben Aïssa, M. S. (2016). Relationship between oil, stock prices and exchange rates: A vine copula based GARCH method. North American Journal of Economics and Finance, 37, 458-471.

3. Bendell, J., and Kearins, K. (2005). The political bottom line: the emerging dimension to corporate responsibility for sustainable development. Business Strategy and the Environment, 14(6), 372-383.

4. Blanchard, O. (1993). Consumption and the recession of 1990-1991. American Economic Review, 83(2), $270-274$.

5. Bollerslev, T. (1986). Generalized autoregressive conditional heteroskedasticity. Journal of Econometrics, 31, 307-327.

6. Carroll, C., Fuhrer, J., and Wilcox, D. (1994). Does Consumer Sentiment Forecast Household Spending? If So, Why? American Economic Review, 84, 1397-1408.

7. Chen, M.-H. (2015). Understanding the impact of changes in consumer confidence on hotel stock performance in Taiwan. International Journal of Hospitality Management, 50, 55-65.

8. Chen, S.-S. (2011). Lack of consumer confidence and stock returns. Journal of Empirical Finance, 18(2), $225-236$.

9. Chen, S.-S. (2012). Consumer confidence and stock returns over market fluctuations. Quantitative Finance, 12(10), 1585-1597.

10. Cont, R. (2001). Empirical properties of asset returns: stylized facts and statistical issues. Quantitative Finance, 1(2), 223-236.

11. Curtin, R. T. (1982). Indicators of Consumer Behavior: The University of Michigan Surveys of Consumers. The Public Opinion Quarterly, 46(3), 340-352.

12. Engle, R. (1982). Autorregressive Conditional Heteroskedasticity with Estimates of United Kingdom Inflation. Econometrica, 50, 987-1008.

13. Hsu, C. C., Lin, H. Y., and Wu, J. Y. (2011). Consumer Confidence and Stock Markets: The Panel Causality Evidence. International Journal of Economics and Finance, 3(6), 91-98.

14. Huth, W. L., Eppright, D. R., and Taube, P. M. (1994). The indexes of consumer sentiment and confidence: Leading or misleading guides to future buyer behavior. Journal of Business Research, 29 (3), 199-206.

15. Ludvigson, S. C. (2004). Consumer confidence and consumer spending. Journal of Economic Perspective, 18(2), 29-50.

16. Nelson, D. B. (1991). Conditional heteroskedasticity in asset returns: a new approach, Econometrica, 59, $347-370$. 
17. Otoo, M. W. (1999). Consumer sentiment and the stock market. Board of Governors of the Federal Reserve System, 1-16.

18. Popa, R. A. (2014). The Corporate Social Responsibility Practices in The Context of Sustainable Development. The case of Romania. 2nd GLOBAL CONFERENCE on BUSINESS, ECONOMICS, MANAGEMENT and TO URISM, 30-31 October, Prague, Czech Republic.

19. Singal, M. (2016). Effect of consumer sentiment on hospitality expenditures and stock returns. International Journal of Hospitality Management, 31(2), 511-521.

20. Sirbu, R. M., Homorodean, A. P., and Draghici, A. (2014). The Sustainability Of Organizations From The Perspective Of Socially Responsible Investments, SEA - Practical Application of Science, 3(5), 585-594. 